\title{
Accident Consequences Analysis of the HYLIFE-II Inertial Fusion Energy Power Plant Design
}

S. Reyes, J.F. Latkowski, J. Gomez del Rio, J. Sanz

U.S. Department of Energy

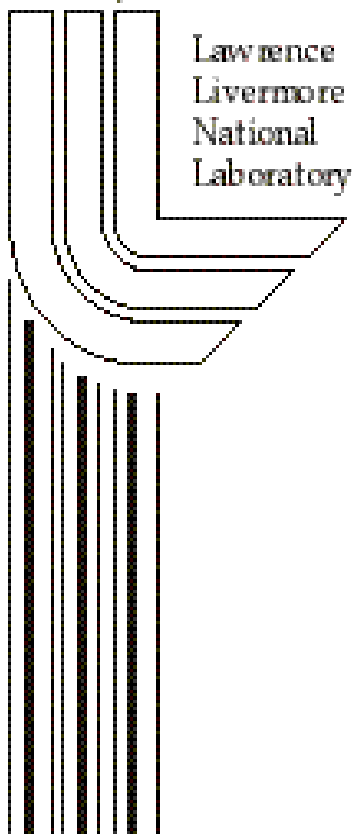

This article was submitted to

$13^{\text {th }}$ International Symposium on Heavy Ion Inertial Fusion, San Diego, CA, March 12-17, 2000

\section{March 1, 2000}




\section{DISCLAIMER}

This document was prepared as an account of work sponsored by an agency of the United States Government. Neither the United States Government nor the University of California nor any of their employees, makes any warranty, express or implied, or assumes any legal liability or responsibility for the accuracy, completeness, or usefulness of any information, apparatus, product, or process disclosed, or represents that its use would not infringe privately owned rights. Reference herein to any specific commercial product, process, or service by trade name, trademark, manufacturer, or otherwise, does not necessarily constitute or imply its endorsement, recommendation, or favoring by the United States Government or the University of California. The views and opinions of authors expressed herein do not necessarily state or reflect those of the United States Government or the University of California, and shall not be used for advertising or product endorsement purposes.

This is a preprint of a paper intended for publication in a journal or proceedings. Since changes may be made before publication, this preprint is made available with the understanding that it will not be cited or reproduced without the permission of the author.

This report has been reproduced directly from the best available copy.

Available to DOE and DOE contractors from the

Office of Scientific and Technical Information

P.O. Box 62, Oak Ridge, TN 37831

Prices available from (423) 576-8401

http:/ / apollo.osti.gov/bridge/

Available to the public from the National Technical Information Service

U.S. Department of Commerce 5285 Port Royal Rd., Springfield, VA 22161

http://www.ntis.gov/

OR

Lawrence Livermore National Laboratory Technical Information Department's Digital Library http:/ /www.llnl.gov/tid/Library.html 


\title{
Accident consequences analysis of the HYLIFE-II Inertial Fusion Energy Power Plant Design
}

\author{
S. Reyes ${ }^{\mathrm{a}, \mathrm{b}}$, J. F. Latkowski ${ }^{\mathrm{a}}, \mathrm{J}$. Gomez del Rio ${ }^{\mathrm{b}}$, and J. Sanz ${ }^{\mathrm{b}}$ \\ ${ }^{a}$ Lawrence Livermore National Laboratory, P. O. Box 808, L-446, Livermore, CA 94550, \\ Tel: 925-423-9378 - Fax: 925-423-4606 \\ ${ }^{b}$ Universidad Nacional de Educacion a Distancia, Escuela Tecnica Superior Ingenieros Industriales, \\ Departamento Ingenieria Energetica, C/ Ciudad Universitaria, s/n, 28040 Madrid, Also: Instituto Fusion Nuclear, Madrid, Spain
}

\begin{abstract}
Previous studies of the safety and environmental (S\&E) aspects of the HYLIFE-II inertial fusion energy (IFE) power plant design have used simplistic assumptions in order to estimate radioactivity releases under accident conditions. Conservatisms associated with these traditional analyses can mask the actual behavior of the plant and have revealed the need for more accurate modeling and analysis of accident conditions and radioactivity mobilization mechanisms. In the present work a set of computer codes traditionally used for magnetic fusion safety analyses (CHEMCON, MELCOR) has been applied for simulating accident conditions in a simple model of the HYLIFE-II IFE design. Here we consider a severe lost of coolant accident (LOCA) producing simultaneous failures of the beam tubes (providing a pathway for radioactivity release from the vacuum vessel towards the containment) and of the two barriers surrounding the chamber (inner shielding and containment building it self). Even though containment failure would be a very unlikely event it would be needed in order to produce significant off-site doses. CHEMCON code allows calculation of long-term temperature transients in fusion reactor first wall, blanket, and shield structures resulting from decay heating. MELCOR is used to simulate a wide range of physical phenomena including thermal-hydraulics, heat transfer, aerosol physics and fusion product release and transport. The results of these calculations show that the estimated off-site dose is less than $6 \mathrm{mSv}(0.6$ rem), which is well below the value of $10 \mathrm{mSv}$ (1 rem) given by the DOE Fusion Safety Standards for protection of the public from exposure to radiation during off-normal conditions.
\end{abstract}

Keywords: IFE safety analysis; Accident consequences, Off-site doses

\section{Introduction}

The HYLIFE-II IFE power plant concept [1] sought to maximize its attractiveness by providing lifetime components, high availability, low cost of electricity and favorable S\&E characteristics. During the original HYLIFE-II study, S\&E goals included:

- low off-site dose from a severe accident

- avoidance of nuclear grade (N-stamp) for most components (requiring less than $0.25 \mathrm{~Sv}$ off-site dose in the event of failure of that component)

- working area dose rates less than 50 $\mu \mathrm{Sv} / \mathrm{hr}$ for low occupational risk

- dose from routine atmospheric effluents less than $50 \mu \mathrm{Sv} / \mathrm{yr}$.

Since that time, the nuclear community (fission and fusion) has reached a consensus and established more restrictive safety goals. The DOE Fusion Safety Standards [2] for public protection in case of accident give a limit off-site dose of $10 \mathrm{mSv}$ (1 rem). This dose is a 50-year committed effective dose to the most exposed individual (MEI) at the site boundary $(1 \mathrm{~km})$ that only includes contributions from direct cloudshine and inhalation during plume passage, because they pose an immediate threat. This value is based upon a 1991 Environmental Protection Agency document that specifies the level at which sheltering and evacuation should be undertaken [3].

This work concentrates in severe accident analysis in order to compare off-site obtained doses to the values provided by DOE Fusion Safety Standards. The present work focuses on what has been considered to be one of the most severe possible accidents in the HYLIFE-II design. We assume a LOCA with loss of all the liquid Flibe and simultaneous break of all the beam tubes, which provides a flow path from the target chamber to the containment. In addition, 
breaks in both the inner shielding wall and the containment building wall are assumed. These breaks provide a pathway for release of radioactive material to the environment.

In order to perform a consequences analysis, first we need to know the source term of radioactivity that is released to the environment. Neutron transport and activation, thermal transients, and aerosol transport calculations have been performed. Given the activity release (in units of $\mathrm{Bq}$ ) and the specific dose of each isotope (in units of $\mathrm{Sv} / \mathrm{Bq}$ ), which has been calculated with MACCS2 code [4], the accident dose may be calculated.

\section{Long-term thermal behavior}

Prior to the calculation of radioactivity release fractions, one needs to know the timetemperature histories of the different reactor components during the accident. This is used to determine the activation products source term available for mobilization, which will later be used as input data for the MELCOR calculations [5].

In this case the only energy source is the radioactive decay heat from the activated material in the reactor components. Once the accident begins, it is conceivable that fusion reactions could continue to occur for a short period of time. Several factors must be considered: accelerator operation, target injection, and beam propagation through a varying environment. If accelerator operation and target injection both continue, then beam propagation ultimately will determine when ignition is no longer possible. We have assumed a complete loss of coolant accident combined with multiple breaks in the beam tubes, shielding, and containment building. These breaks will allow air to enter the beam tubes and chamber, and this air will result in the inability to propagate the heavy ion beams to the target.

Langdon discusses the pressure of gas that is allowable for successful beam propagation [6]. For an unneutralized beam, a background pressure of more than $13 \mathrm{~Pa}$ (conservatively assuming lithium gas) guarantees that stripping and plasma instabilities will destroy the beam. For a fully neutralized beam, a pressure of about $2700 \mathrm{~Pa}$ will produce multiple scattering, which will destroy propagation. If we conservatively assume that the beams are fully neutralized, then fusion yield might continue until enough air enters the beam tube to raise the pressure to 2700 $\mathrm{Pa}$.

To determine the time required to reach $2700 \mathrm{~Pa}$ within the beam tubes, a simple MELCOR calculation was performed. We see that $2700 \mathrm{~Pa}$ is reached within only $50 \mathrm{~ms}$, and thus, a plant operating at $6.4 \mathrm{~Hz}$ will not be able to ignite the next target before beam propagation is halted due to air pressure.

Considering then that decay heat from activated materials is the only existing source available for heat transfer, a CHEMCON [7] calculation was developed using a simple 1-D cylindrical model. This model consists of four stainless steel shells that represent the tubes containing the Flibe, first structural wall, blanket structure and vacuum vessel, a inner concrete shield and the containment building wall. Conduction, convection and radiation heat transfer was calculated between these structures. The activation and decay heat results were obtained from the ACAB [8] activation code following 30 years of plant operation. Fluxes in structures were calculated with TART [9] Monte Carlo neutron transport code. Figure 1 shows the thermal transient in the different reactor components due to the decay heat from the activation products.

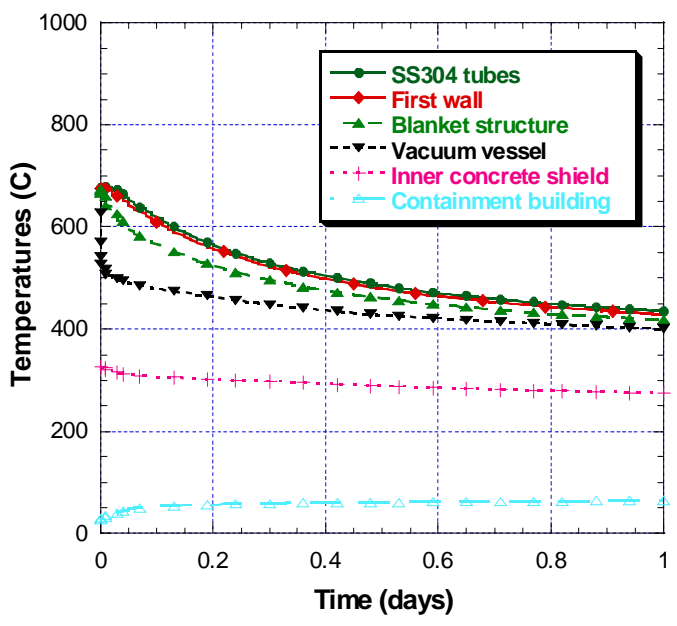

Fig. 1. Temperature evolution in the various reactor components during the first day following the accident.

The first wall temperature displays a mild peak at $679{ }^{\circ} \mathrm{C}$ at about 0.01 days, after which it gradually falls. This indicates that the radioactive afterheat is low enough to avoid melting of the stainless steel structure $\left(\mathrm{T}_{\text {melt }} \sim 1400{ }^{\circ} \mathrm{C}\right)$. This 
result eliminates the possibility of volatilization of the stainless steel structures during the accident, which would result in a significant increase in the radioactive mobilized mass.

In order to protect the first structural wall from direct neutron fluxes, the updated HYLIFEII design considers a Flibe pocket $60 \mathrm{~cm}$ thick, which is the value used in our final accident analysis. A parametric study was developed in order to evaluate the benefit of a thick liquid wall on the activation of the structures and accident temperatures. ACAB calculations were performed for different Flibe pocket thickness and irradiation times of 3 and 30 years irradiation. Figure 2 shows the maximum accident temperatures obtained with CHEMCON for the different cases.

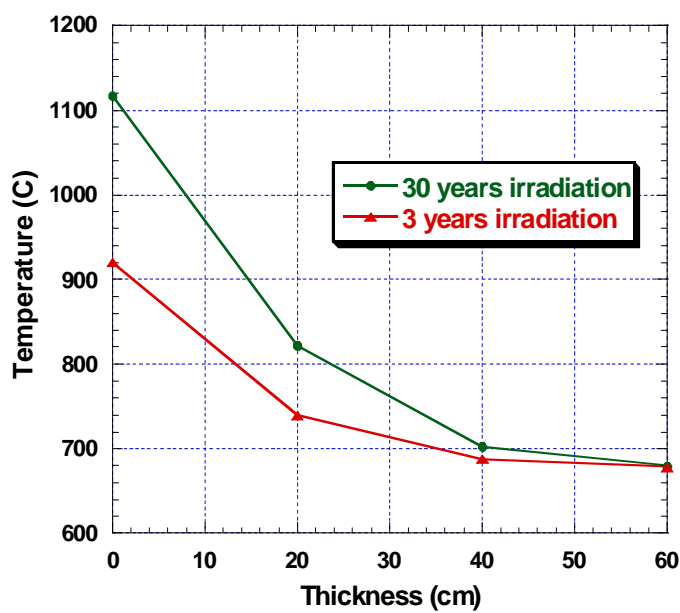

Fig. 2. Maximum accident temperatures reached at the first structural wall for different Flibe pocket thickness.

It can be observed that an unprotected wall would not reach the melting point either. This result is very important when accounting for the stainless steel mobilized masses. Figure 2 also shows the benefit of introducing a thick liquid protection. For example, note that for thickness > $15 \mathrm{~cm}$, a 30-yr protected wall is better than a $3-y r$ unprotected wall in terms of maximum accident temperature.

\section{Activation products source term}

There are four main sources of radioactivity that must be considered in HYLIFE-II. First, the $\mathrm{X}$-rays from each target vaporize about $10 \mathrm{~kg}$ of Flibe. Although we assume a total LOCA, our analyses conservatively include this Flibe aerosol with its activation products.
Second, it is estimated that approximately $140 \mathrm{~g}$ of tritium would be trapped within the chamber, blanket, and piping [1]. We assume that entire tritium inventory is converted to the more radiotoxic HTO form. This yields a mass of HTO aerosol of $930 \mathrm{~g}$, which we round up to $1 \mathrm{~kg}$.

Third, we assume that the corrosion of type 304 stainless steel (SS304) by Flibe within the chamber and blanket can be limited to $1 \mu \mathrm{m} / \mathrm{y}$ via corrosion control methods. Additionally, we assume that the Flibe clean-up system can maintain the mobilizable inventory of corrosion products to a 1-y supply. Given a total surface area of $1040 \mathrm{~m}^{2}$, we obtain a corrosion product inventory of $8.3 \mathrm{~kg}$ in the total Flibe volume.

Finally, we use data from oxidation-driven mobilization experiments on PCA performed at the Idaho National Engineering and Environmental Laboratory (INEEL) to calculate an additional $0.5 \mathrm{~kg}$ of SS304 (we assume that SS304 mobilization will be the same as that from PCA) that is mobilized under exposure to steam at the accident temperatures previously calculated [10,11]. Adding this $0.5 \mathrm{~kg}$ to the 8.3 $\mathrm{kg}$ of corrosion products, we have $\sim 9 \mathrm{~kg}$, which we round up to $10 \mathrm{~kg}$ of SS304. Considering that only about $5 \%$ of the Flibe is present in the chamber at any given time, we end up getting 0.5 $\mathrm{kg}$ of SS304 as corrosion and oxidation products.

It is worth noting that we are being quite conservative in assuming that the corrosion products will be in an aerosol form and available for mobilization (one could make an argument that the corrosion products would leave with the Flibe during the LOCA). Additionally, our assumption of steam oxidation driven mobilization is conservative - there is no clear mechanism for sending steam to the chamber. At temperatures of interest, oxidation-driven mobilization from PCA under exposure to air occurs at a rate that is $\sim 900 \times$ lower than that under exposure to steam.

\section{Radioactivity release and off-site doses}

To estimate release fractions, a MELCOR model of HYLIFE-II was developed. This model consists of four stainless steel shells, which represent the SS304 tubes, first wall, blanket structure and vacuum vessel, a concrete inner shield and the containment building. The beam tubes were also modeled, considering an updated 
HYLIFE-II version that includes 96 beams per side. Beam tubes and volumes within the vacuum vessel are assumed to be at vacuum. The SS304 shells are initially at their operating temperature of $675^{\circ} \mathrm{C}$.

The radioactive source term described in the previous section is used as input data for the masses of activated material that is available for mobilization during the transient.

We have considered a severe accident consisting of a total LOCA, with loss of all the liquid Flibe, with simultaneous failure of the beam tubes, the concrete inner shielding and the containment. The total failure of the beam tubes (the area of the break is modeled as the calculated area of the total number of beams) means that the inner volumes are going to have a flow path towards the outer volumes, which are filled with air at atmospheric pressure. Both the inner shield and containment walls are initially at an estimated temperature of $32^{\circ} \mathrm{C}$. Additionally, we assume a double failure of the inner shielding and concrete building (each of these breaks is 1 $\mathrm{m}^{2}$ in area) that provides a pathway to the environment. This model is used by MELCOR to simulate the progression of the accident.

The MELCOR heat transfer package considers conduction, convection and radiation between the structures. The aerosol transport module treats SS304 and Flibe aerosol nucleation and agglomeration, vapor condensation, gravity settling and gaseous/liquid transport. A new module introduced by INEEL allows simulation of HTO transport and condensation. Calculations of tritium migration from the stainless steel shells were also developed using TMAP (Tritium Migration Analysis Program) rather than assuming an instantaneous liberation from the structures. These calculations showed that at the operating temperature of $675{ }^{\circ} \mathrm{C}$, the tritium migration from the steel is fast enough $(>90 \%$ in only 1.5 hour) that there is no difference when comparing with the results from the instantaneous migration assumption [12].

The transient is considered to be one month long. Figure 3 shows the fraction of the source term masses that are released to the environment during the accident. It can be noticed that after about 7 days all the aerosol masses inside the reactor have been deposited (condensed in the case of HTO), and no more radioactive material is released.

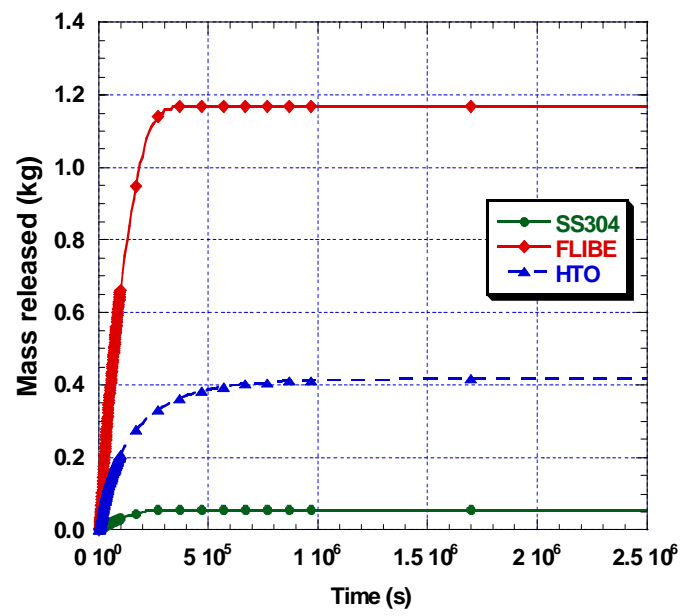

Fig. 3. Masses of activated material released to the environment during a period of one month following the accident.

As Figure 3 shows, of the $0.5 \mathrm{~kg}$ of SS304 that is mobilized, only $5.56 \times 10^{-2} \mathrm{~kg}$ is released to the environment. Approximately $1.2 \mathrm{~kg}$ (out of $10 \mathrm{~kg}$ ) of Flibe is released. Finally, less than $50 \%$ of the HTO is released. We conservatively round this value up to $50 \%$.

With these data about the activity released in $\mathrm{Bq}$, and the adequate dose conversion factors (DCF) in Sv/Bq, off-site doses can be obtained. Of the total inventory in the reactor at the moment of shutdown (just before the accident happening), all the radionuclides whose contribution to the radioactivity release was above $3.7 \times 10^{7} \mathrm{~Bq}(1 \mathrm{mCi})$ were considered for dose calculation purposes. The DFC library has been updated to include radionuclides that were missing from traditional (fission) libraries as some of these radionuclides maybe important for fusion doses. Data on DCF were calculated when necessary using MACCS2 code. The kind of dose we used to compare with the Fusion Safety Standard limit $(10 \mathrm{mSv}=1 \mathrm{rem})$, was the equivalent effective dose with 50 years commitment, resulting from the exposure during the plume passage. In addition to direct cloudshine and inhalation during plume passage, our doses also consider contributions from groundshine, and inhalation of resuspended material.

With these assumptions the results show that the predominant dose is from the tritium in HTO form, which gives a total of $5.3 \times 10^{-3} \mathrm{~Sv}(0.53$ 
rem). Both the SS304 and the Flibe make small contributions to the total dose, being $4.3 \times 10^{-5}$ $\mathrm{Sv}\left(4.3 \times 10^{-3} \mathrm{rem}\right)$ and $5.64 \times 10^{-4} \mathrm{~Sv}\left(5.64 \times 10^{-2}\right.$ rem), respectively. The summation of these three quantities results in a total dose of $5.9 \mathrm{mSv}(0.59$ rem).

It should be pointed out that about $75 \%$ of the SS304 dose comes from ${ }^{60} \mathrm{Co}$, and for the Flibe, ${ }^{18} \mathrm{~F}$ is the only contributor to the dose. From the total activity due to ${ }^{18} \mathrm{~F}$ at the moment of the reactor shutdown $\left(1.26 \times 10^{19} \mathrm{~Bq}=340\right.$ $\mathrm{MCi})$, only $8.63 \times 10^{14} \mathrm{~Bq}(0.023 \mathrm{MCi})$ are vaporized and available for mobilization during the accident. The final quantity of activity from the ${ }^{18} \mathrm{~F}$ that is released to the environment is 1.01 $\mathrm{x} 10^{14} \mathrm{~Bq}\left(2.73 \times 10^{3} \mathrm{Ci}\right)$.

The final result is that even with the various conservatisms introduced in the calculation, the off-site accident dose is under $6 \mathrm{mSv}$ (0.6 rem). This is a relevant result given that it is below the limit of $10 \mathrm{mSv}$ (1 rem) given in the DOE Fusion Safety Standards, which means no sheltering and evacuation needed.

\section{Conclusions and future work}

The primary goal of accident consequence analyses is to integrate the findings of the accident scenarios with the materials mobilization data and dust/aerosol transport modeling to estimate radiation doses under accident conditions. Doses and the consequences of those doses must be calculated to enable direct comparison of IFE hazards with those associated with fission and non-nuclear systems.

In the present work accident consequences have been analyzed for the HYLIFE-II IFE design. A severe LOCA with failure of the beam tubes, and double failure in the inner concrete shielding and containment building has been simulated using fusion safety codes.

The long-term thermal study of the various reactor components has shown that the decay heat from activation products is low enough so that there is no melting of structures during the accident and temperatures reach a mild peak over the operational values before they start dropping.

The off-site dose released in this accident has been calculated to be less than $6 \mathrm{mSv}(0.6$ rem). This result is well below the limit given by the Fusion Safety Standards of $10 \mathrm{mSv}$ (1 rem) during an off-normal event in order to avoid public sheltering and evacuation. We can conclude that the HYLIFE-II design has very favorable safety characteristics according to this analysis.

Additional work is needed to identify and simulate other accident scenarios in order to make a complete safety analysis for HYLIFE-II. Accidents that do not involve a total LOCA will have to make use of the equation of state of Flibe, which will have to be introduced in MELCOR code. Also other IFE designs must be considered and analyzed in a similar way to have a wider perspective of the attractiveness of IFE designs from a safety and environment point of view.

\section{Acknowledgements}

Work performed under the auspices of the U.S. Department of Energy by University of California Lawrence Livermore National Laboratory under contract No. W-7405-Eng-48 and under support of scholarship from UNED, Madrid, Spain.

\section{References}

[1] R. W. Moir, et al., Fus. Technol. 25 (1994) 5-25.

[2] "Safety of Magnetic Fusion Facilities: Guidance," DOE-STD-6003-96, U. S. Department of Energy, Washington, D. C. (1996).

[3] "Manual of Protective Action Guides and Protective Action for Nuclear Incidents, "PB92-164763, U. S. Environmental Protection Agency, Washington, D. C. (1991).

[4] D. Chanin and M. L. Young, NUREG/CR-6613, Vol. 1, SAND97-0594 (1998).

[5] R. O. Gauntt, R. K. Cole, S. A. Hodge, S. B. Rodriguez, R. L. Sanders, R. C. Smith, D. S. Stuart, R. M. Summers and M. F. Young, NUREG/CR-6119, Vol. 1, Rev. 1, SAND97-2398 (1997).

[6] A. B. Langdon, Particle Accelerators, 37 (1992) 175180.

[7] M. J. Gaeta and B. J. Merrill, Idaho National Engineering and Environmental Laboratory, INEL95/0147 (1995)

[8] J. SANZ, Universidad Nacional de Educacion a Distancia (UNED), Lawrence Livermore National Laboratory, UCRL-CR-133040 (1999).

[9] D. E. CULLEN, Lawrence Livermore National Laboratory, UCRL-ID-126455, Rev. 2 (1998).

[10] K. A. McCarthy, G. R. Smolik, D. L. Hagrman, and D. A. Petti, J. Nucl. Mater. 233-237 (1996) 1607-1611.

[11] G. R. Smolik, W. J. Carmack, and K. Coates, Idaho National Engineering and Environmental Laboratory, ITER/US/97/TE/SA-25 (1997).

[12] Rion Causey and Thomas Venhaus, personal communication (2000). 